\title{
Counseling on the Use of Over-the-counter and Limited-Free Medicines for Recitation Mothers in Cibungur Village, Tasikmalaya, Indonesia
}

\author{
Fahmi Sidiq \\ Department of Pharmacy, Universitas Perjuangan, Tasikmalaya, Indonesia \\ Corresponding author email: fahmisidiq78@gmail.com
}

\begin{abstract}
Over-the-counter medicines can be purchased without a doctor's prescription and can be purchased at pharmacies and licensed drugstores to treat non-specific minor illnesses. Limited over-the-counter drugs, also known as list W drugs (W: Waarschuwing = warning/alert) are strong drugs that can be purchased without a doctor's prescription, but their use must pay attention to the drug information on the packaging. The results of this counseling are the mothers of recitation in Cibungur village, Parungponteng subdistrict, namely knowing about, how to use, get, store and dispose of good and correct medicines. The selection of over-thecounter and over-the-counter drugs is limited. As well as the characteristics of damaged drugs. people are becoming more careful in the use of drugs. Therefore, the University Pharmacy Study Program takes the initiative to provide community service by providing over-the-counter and limited-free drugs and ways to find out damaged drugs.
\end{abstract}

Keywords: Education, over-the-counter drugs, limited over-the-counter drugs, damaged drugs and Beyond Use Date

\section{Introduction}

Drugs are materials or combinations of materials, including biological products used to influence or investigate them, physiological systems or pathological conditions in the context of determining diagnosis, prevention, healing, recovery, health improvement and contraception for humans (Gardner et al., 2004). First, these substances are formed into pharmaceutical preparations such as capsules, pills, tablets, syrups, powders, suspensions, ointments, suppositories and others (Drumond et al., 2017).

Treatment has a purpose, namely as a diagnosis, to beautify or beautify the body or parts of the human body. as a preventive measure (preventive), and healing (curative), symptomatic (Bartl and Frisch, 2009). Treatment can also play a role in the recovery process (rehabilitative) and health improvement (promotive) as well as contraception.

Drugs are like two sides of a coin, where one side can work as a drug, on the other hand it can also work as a poison, depending on the dose used. This means that each drug has a different benefit and risk ratio and this limit is a measure of the safety of a drug. Therefore, the use of drugs must be careful especially for children. Children compared with adults have different responses to drug administration (Tamargo et al., 2017). This is because the physiological organs of children are not yet fully developed so that the action of drugs and the pharmacokinetic profile of drugs in children will be different from those of adults. Likewise with the problem of the right drug dosage form for children is not available, so that errors can occur in the administration of drug doses. All of these have the potential for drug incidents in children (Fortescue et al., 2003; Kaushal et al., 2015).

Most people are used to keeping their own medicine in an effort to self-medicate. Self-medication is usually for standard illnesses or self-medication drugs such as fever, cold, flu, cough, ulcer and other standard diseases (Banerjee and Bhadury, 2012). These standard medicines usually consist of various preparations in the form of tablets, capsules, or syrups (Arya et al., 2010). These drugs are only used situationally (in certain situations), when needed, and then stored back in the cupboard until one day they are needed again. This residual medicine could be because the amount of medicine that is not used is still a lot even though the symptoms of the disease or the disease itself have healed so it is a shame if the rest of this medicine has to be thrown away (Kenny, 1967).

Beyond Use Date (BUD) is the time limit for using a medicinal product after it has been formulated/prepared or after its primary packaging has been opened/damaged (Struble et al., 2019). Primary packaging here means packaging that is in direct contact with the drug substance, such as: bottles, ampoules, blister vials, etc. The definition of BUD is different from the expiration date (ED) because ED describes the time limit for using a drug product after it is produced by a pharmaceutical manufacturer, before the packaging is opened. BUD can be equal to or shorter than ED (Chang et al., 2013). ED is listed by pharmaceutical manufacturers on drug product packaging, while BUD is not always listed (Herawati, 2012). 
Ideally, BUD and ED are determined based on the results of drug product stability tests and are listed on the packaging. BUD and ED determine the time limit in which a drug product is still in a stable state (Giacomel et al., 2013). A drug product that is stable means that it has chemical, physical, microbiological, therapeutic, and toxicological characteristics that do not change from the specifications set by the drug manufacturer, both during storage (Herawati, 2012).

Self-medication should only be carried out for minor illnesses and aims to reduce symptoms, using drugs can be used without a doctor's prescription in accordance with applicable laws and regulations. In order to carry out selfmedication correctly, the public needs clear, correct and reliable information, so that the determination of the type and amount of medicine needed must be based on the rational use of the drug (Hughes et al., 2001).

Over-the-counter drugs can be purchased without a doctor's prescription and can be purchased at pharmacies and licensed drugstores to treat non-specific minor illnesses (Blenkinsopp and Bradley, 1996). Over-the-counter drugs are relatively the safest, may be used to treat mild symptomatic diseases that mostly suffer from the wider community whose treatment can be carried out by the patient himself or self-medication (self-administration or self-medication) (Illhan et al., 2009). This drug has been used in scientific (modern) medicine and has been shown to pose no alarming risk of harm.

Limited over-the-counter drugs, also known as list $\mathrm{W}$ drugs (W: Waarschuwing $=$ warning/alert) are strong drugs that can be purchased without a doctor's prescription, but their use must pay attention to the drug information on the packaging (Cranz, 1990). The sale has a limit on the amount and content of efficacious contents that must be accompanied by a warning sign, warning P1 - P6. Restricted can only be purchased at pharmacies or licensed drugstores. Limited over-the-counter drugs are relatively safe as long as they comply with the rules of use.
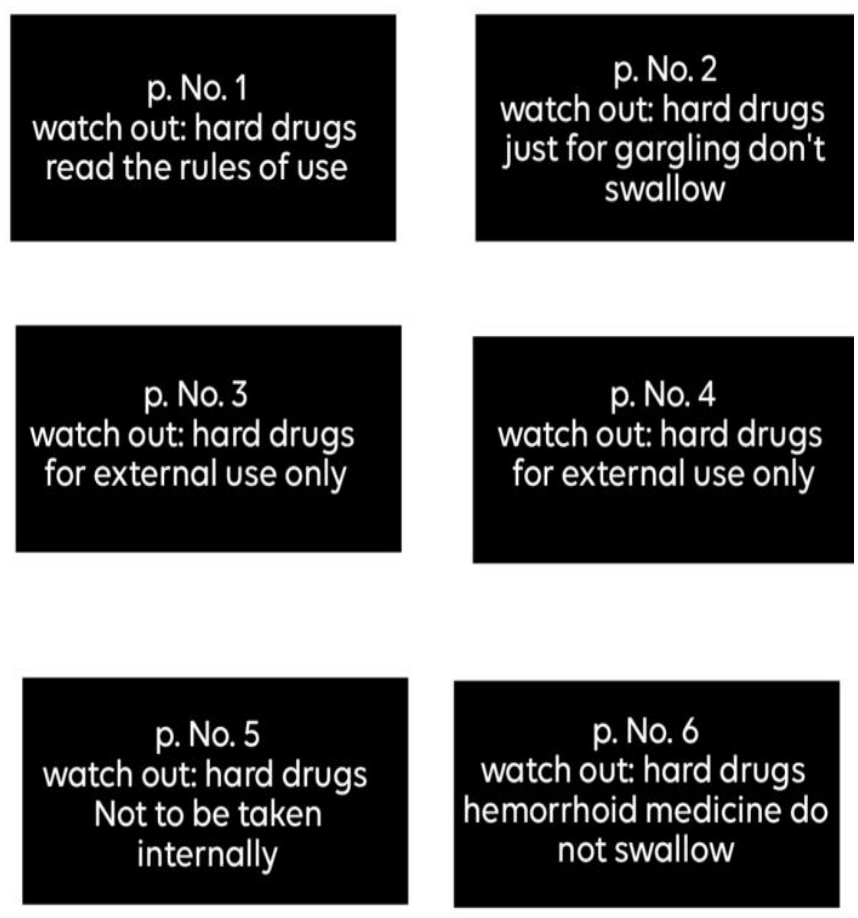

Figure 1. Cibungur village office, Parungponteng sub-district

Mignani et al. (2013) explained that there are several routes of drug use, including: through oral, injection, inhalation, through the mucous membranes, such as through the eyes, ears, and rectum, and through the skin or topically.

One of the responsibilities of pharmacists is to provide information on how to use drugs and the time limit for using drugs after the packaging is opened (providing information about the BUD or ED) so that the drugs used later have guaranteed drug stability both in terms of effectiveness and safety (Keram and Williams, 1988). This counseling aims to increase public knowledge about beyond use date on various types of drug preparations. The level of public knowledge about over-the-counter and limited over-the-counter drugs and BUD. With this counseling, it is hoped that the mothers of recitations in Cibungur Village, Taasikmalaya can use drugs correctly, both in use, as well as storage and expiration dates. 


\section{Methodology}

This counseling was carried out at the Almuhajirin Mosque which is located in Cipicung Village, Cibungur Village, Parungponteng District, Tasikmalaya Regency, West Java Province, Indonesia (See Figure 1).

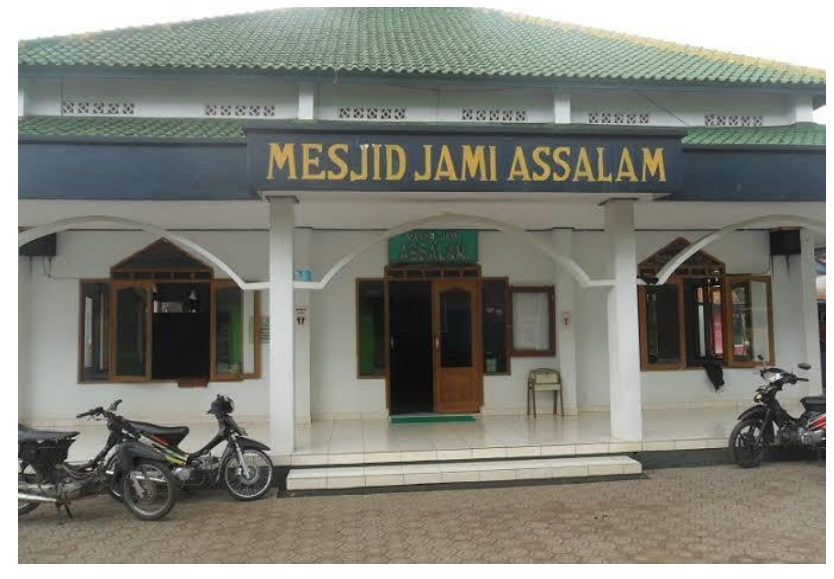

Figure 2. Cibungur village office, Parungponteng sub-district

This activity is carried out using the extension method. The implementation of this service activity goes through the following stages:

Conduct a survey to identify site conditions in the field. At the beginning of the activity, a survey was conducted to see the condition of the field location. Some of the criteria in this survey are environmental conditions that are very supportive of knowledge about the use of free and hard drugs.

Data Collection Techniques Data collection techniques using observation are data collection carried out by the author through observation and using interviews, namely holding direct interviews with informants. Interviews were conducted on selected informants and respondents and were considered capable of providing information regarding the focus of the research problem.

Planning a place for service training activities. From the results of the survey, it was determined the recitation mothers in Cibungur Village, Parungponteng District. as a place for outreach. Things to prepare are:

- The readiness of the apparatus to accept the service team

- Facility readiness

- Making a dedication invitation

- Preparation of counseling materials by the presenting team

- Execution time agreement

\section{Results and Discussion}

Cibungur village is one of the villages in Parungponteng district, the distance from the sub-district capital is $3 \mathrm{Km}$ via the Tasikmalaya Regency Road which is a mountainous and hilly area. The activities that we have carried out have received permission from the head of the Cibungur village and we have conveyed an outline of the activities that will be carried out for a full month starting from the observation program, education about over-the-counter drugs, limited over-the-counter drugs, damaged drugs and drugs that have been used. opened the package (See Figure 2).

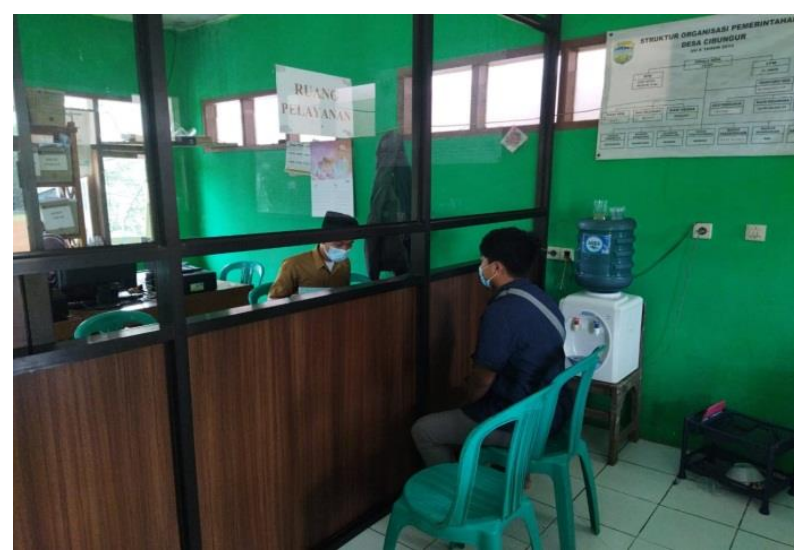

Figure 2. permission and give it to the head of the Cibungur village 
Home medicine storage is a process to store medicines consumed at home. Drugs are chemical compounds that can react to external stimulants such as heat, humidity, light, etc. In some cases, the reaction between the drug and the environment only causes a change in its external form, such as a color change. But in other cases, the reactions that occur can cause serious problems because they affect the effectiveness or efficacy of the drug or even cause side effects in the patient.

Over-the-counter medicines are usually only used by someone who is experiencing minor health problems such as colds, fever, and so on so that they are able to do self-healing or self-medication without having to wait for a doctor's prescription.

Over-the-counter drugs can also be called OTC drugs or over. The Counter drugs, which means the same as overthe-counter drugs themselves, which can be purchased without a prescription from a doctor. Anyone is strongly discouraged from doing trials by mixing over-the-counter drugs with one another in order to get faster or instant results. Always pay attention to the condition of over-the-counter medicines that you will use, because even though there are drug and food regulatory agencies that always carry out inspections to maintain the quality of medicines, however, many irresponsible parties may still sell over-the-counter medicines that have expired or damaged product packaging. and allow contamination of the drug product.

Always pay attention to the packaging of over-the-counter drugs that you buy, pay attention to the expiration date, read carefully the composition and procedures for using the drug, make sure the drug has an official production permit, also read the contra - indications of drugs or other drugs that you should not take when using these drugs, how to store it properly and correctly, as well as the side effects that the drug will cause after you take it.

Selection of drugs and self-medication using drugs that are at home or which can be obtained at pharmacies around the Cibungur Village. The results of the activities in the form of documentation in Lombongo Village obtained from providing information about over-the-counter and limited-free drugs to the community as self-medication capital for the surrounding community.

The public knows the meaning of over-the-counter drugs and limited over-the-counter drugs as well as the p6 sign. This is a good step so that people are more careful in choosing drugs and using drugs which are due to ignorance about drugs that were originally intended to cure diseases caused by wrong use of drugs. buying drugs will actually be very detrimental. And not all over-the-counter drugs can be purchased in the amount you want.

Besides that, we also provide some tips that you can do to be safe in using limited over-the-counter drugs: always follow the instructions for use listed on the packaging, label, or drug brochure, find out the ingredients contained in the drug, especially if you have allergies to certain drugs, give the right medicine with the right dose because the same brand of medicine can contain different medicines (eg medicines for babies, toddlers, and adults), love the pharmacist or doctor about food or medicine that can be taken at the same time as the limited over-the-counter medicine you are taking, use the device that came with the medication. do not use a kitchen spoon to give medicine to drink. store in the right place, love the pharmacist about storing leftover drugs according to their type, and keep them out of reach of children.

to find out damaged medicines which have the characteristics of changing shape, color and taste, spots appear, moist, soft, wet and sticky, and damaged packaging/containers. As for liquid preparations, namely changing color, smell and taste, cloudy, thickening, settling, separating into two phases and people are becoming more careful again in the use of drugs (See Figure 3).

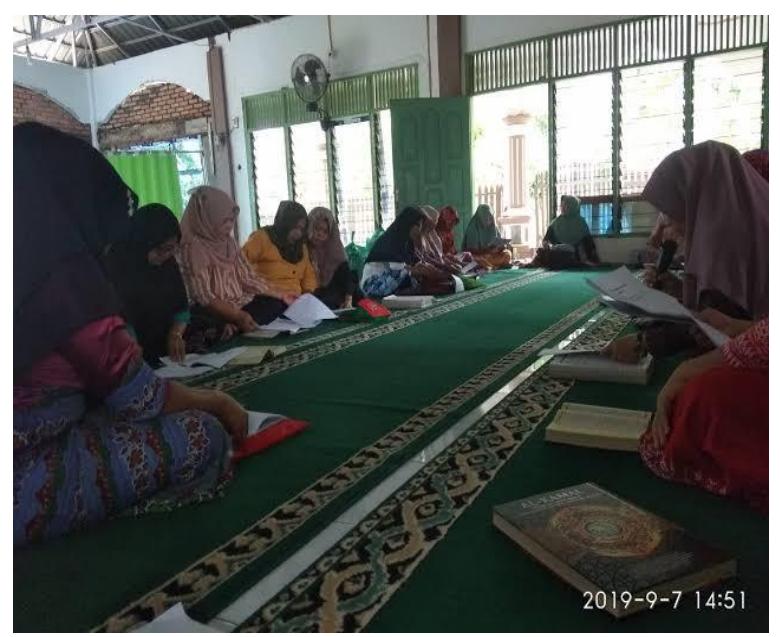

Figure 3. Al-Ikhlas mosque recitation mothers

After the community service activities, it is hoped that they will be more consistent in selecting and be more careful in selecting drugs and storing drugs according to the type of drug. Storage in accordance with the temperature does not reduce the efficacy of the drug and is more durable and good for use. 


\section{Conclussion}

Limited over-the-counter drugs, also known as list w drugs (w: waarschuwing = warning/alert) are strong drugs that can be purchased without a doctor's prescription but their use must pay attention to the drug information on the packaging. beyond use date (bud) is the time limit for using a medicinal product after it has been formulated/prepared or after its primary packaging has been opened/damaged.

Based on the interpretation of the data from the observations that have been made, it can be concluded that the conclusions obtained from the implementation of this activity increase the knowledge of recitation mothers in the Cibungur village. What we do is provide material about over-the-counter drugs and limited over-the-counter drugs as well as provide tips to be safe in using limited over-the-counter drugs, which is expected with these tips to make it easier for mothers of religious teachers in Cibungur village to understand. this shows that the level of knowledge of the community can increase along with the entry of information obtained from both formal and non-formal education that can have a short-term effect, besides the habits and traditions carried out by respondents without going through good or bad reasoning, thereby increasing respondents' knowledge .

\section{References.}

Arya, A., Chandra, A., Sharma, V., \& Pathak, K. (2010). Fast dissolving oral films: an innovative drug delivery system and dosage form. International Journal of ChemTech Research, 2(1), 576-583.

Banerjee, I., \& Bhadury, T. (2012). Self-medication practice among undergraduate medical students in a tertiary care medical college, West Bengal. Journal of postgraduate medicine, 58(2), 127.

Bartl, R., \& Frisch, B. (2009). Osteoporosis: diagnosis, prevention, therapy. Berlin: Springer Science \& Business Media.

Blenkinsopp, A., \& Bradley, C. (1996). Over the Counter Drugs: Patients, society, and the increase in self medication. Bmj, 312(7031), 629-632.

Chang, X., Xu, T., Li, Y., \& Wang, K. (2013). Dynamic modular architecture of protein-protein interaction networks beyond the dichotomy of 'date'and 'party'hubs. Scientific reports, 3(1), 1-8.

Cranz, H. (1990). Over-the-counter drugs. Drug Safety, 5(1), 120-125.

Drumond, N., van Riet-Nales, D. A., Karapinar-Çarkit, F., \& Stegemann, S. (2017). Patients' appropriateness, acceptability, usability and preferences for pharmaceutical preparations: Results from a literature review on clinical evidence. International journal of pharmaceutics, 521(1-2), 294-305.

Fortescue, E. B., Kaushal, R., Landrigan, C. P., McKenna, K. J., Clapp, M. D., Federico, F., \& Bates, D. W. (2003). Prioritizing strategies for preventing medication errors and adverse drug events in pediatric inpatients. Pediatrics, 111(4), 722-729.

Gardner, C. R., Walsh, C. T., \& Almarsson, Ö. (2004). Drugs as materials: valuing physical form in drug discovery. Nature Reviews Drug Discovery, 3(11), 926-934.

Giacomel, C. B., Dartora, G., Dienfethaeler, H. S., \& Haas, S. E. (2013). Investigation on the use of expired make-up and microbiological contamination of mascaras. International journal of cosmetic science, 35(4), 375-380.

Herawati, F. (2012). Beyond Use Date Produk Steril. Buletin Rasional, 10(3), 22-24.

Hughes, C. M., McElnay, J. C., \& Fleming, G. F. (2001). Benefits and risks of self medication. Drug safety, 24(14), $1027-1037$.

İlhan, M. N., Durukan, E., Ilhan, S. Ö., Aksakal, F. N., Özkan, S., \& Bumin, M. A. (2009). Self-medication with antibiotics: questionnaire survey among primary care center attendants. Pharmacoepidemiology and drug safety, 18(12), 1150-1157.

Kaushal, R., Bates, D. W., Landrigan, C., McKenna, K. J., Clapp, M. D., Federico, F., \& Goldmann, D. A. (2001). Medication errors and adverse drug events in pediatric inpatients. Jama, 285(16), 2114-2120.

Kenny, T. (1967). The influence of mineral composition on the residual strength of natural soils. In Proc. Geotecnical conference, Oslo, 1967 (Vol. 1, pp. 123-129).

Keram, S., \& Williams, M. E. (1988). Quantifying the ease or difficulty older persons experience in opening medication containers. Journal of the American Geriatrics Society, 36(3), 198-201.

Mignani, S., El Kazzouli, S., Bousmina, M., \& Majoral, J. P. (2013). Expand classical drug administration ways by emerging 
routes using dendrimer drug delivery systems: a concise overview. Advanced drug delivery reviews, 65(10), 1316-1330.

Struble, C. A., Ellis, J. D., \& Lundahl, L. H. (2019). Beyond the bud: emerging methods of cannabis consumption for youth. Pediatric Clinics, 66(6), 1087-1097.

Tamargo, J., Le Heuzey, J. Y., \& Mabo, P. (2015). Narrow therapeutic index drugs: a clinical pharmacological consideration to flecainide. European journal of clinical pharmacology, 71(5), 549-567. 